\title{
PSEUDOCISTO ESPLÊNICO NÃO PARASÍtICO: UM RELATO DE CASO
}

\section{NON-PARASITIC SPLENIC CYST: A CASE REPORT}

\author{
Alice de Moraes Baier ${ }^{1}$, Paola de Oliveira Abreu ${ }^{1}$, \\ Mônica Ribeiro de Campos ${ }^{1}$, Julia Casani ${ }^{1}$, \\ Luiz Fernando Maculan Ferreira', Claus Dieter Dummer²
}

\begin{abstract}
RESUMO
Os cistos esplênicos são raros, podem ser congênitos ou adquiridos e são encontrados, muitas vezes, em exames incidentais. Aparecem como tumorações na topografia do hipocôndrio esquerdo, associados a sintomas obstrutivos e dor abdominal. Os pseudocistos são formados por uma camada de tecido fibroso, sem revestimento epitelial, e têm como fator etiológico mais provável o trauma esplênico prévio. Atualmente, o ultrassom abdominal é o método mais importante para o diagnóstico de cisto esplênico, pois evita a realização de exames mais agressivos. Para o tratamento de cisto esplênico sintomático de grande tamanho, não parasítico, com risco aumentado de ruptura e etiologia desconhecida, a indicação de escolha é a esplenectomia. Este relato objetiva apresentar essa doença incomum, ressaltando seu quadro clínico, métodos diagnósticos e tratamento.
\end{abstract}

Palavras-chave: Pseudocisto; baço; esplenectomia

\section{ABSTRACT}

Splenic cysts are rare, can be congenital or acquired, and are most often found in incidental exams. They appear as tumors in the left hypochondrium, in association with obstructive symptoms and abdominal pain. Pseudocysts are formed by fibrous tissue layer, without epithelial coating, and their most probable cause is previous splenic trauma. Nowadays, abdominal ultrasound is the most important method for the diagnosis of splenic cyst, avoiding more aggressive exams. For symptomatic, large, non-parasitic splenic cysts with high risk of rupture and unknown etiology, splenectomy is indicated. This report intends to present this uncommon disease, emphasizing its clinical condition, diagnostic methods, and treatment.

Keywords: Pseudocyst; spleen; splenectomy

Cistos esplênicos são tumores abdominais incomuns que foram classificados por Martin et al. ${ }^{1}$ em tipo I (primários ou verdadeiros) e tipo II (secundários ou pseudocistos). Os cistos tipo I são cistos com cápsula epitelial, que podem ser de natureza parasitária ou não. Os cistos tipo I não parasitários podem ser de origem congênita, vascular ou neoplásica. Os cistos tipo II não possuem cápsula e são comumente encontrados após trauma esplênico contuso. A laparotomia com esplenectomia tem sido o método de escolha para o tratamento de muitos cistos esplênicos ${ }^{2,3}$. Cistos esplênicos são lesões raras com aproximadamente 800 casos descritos na literatura mundial até o ano de 2009.

\section{RELATO}

Paciente masculino, 39 anos, branco, com história de dor lombar direita iniciada na região hipogástrica, sem sintomas urinários associados. Ao exame físico, encontrava-se afebril, com dor à palpação de flanco direito e punho
Clin Biomed Res. 2017;37(2):143-145

1 Curso de Medicina, Departamento de Biologia e Farmácia, Universidade de Santa Cruz do Sul (UNISC). Santa Cruz do Sul, RS, Brasil.

2 Curso de Medicina, Departamento de Biologia e Farmácia, Hospital Santa Cruz. Santa Cruz do Sul, RS, Brasil.

Autor correspondente: Alice de Moraes Baier alice.moraesbaier@hotmail.com Hospital Santa Cruz

Rua Fernando Abott, 174. 96810-150, Santa Cruz do Sul, RS, Brasil. 
percussão lombar positiva à direita. A ecografia abdominal revelou cisto renal direito de $1,2 \mathrm{~cm}$ e cistos no fígado e no baço de $4,5 \mathrm{~cm}$. A sorologia para hidatidose foi negativa. Optou-se por tratamento conservador com ecografia para controle dos cistos em 6 meses. Na consulta de controle, o paciente encontrava-se assintomático e a ecografia abdominal revelava dimensões inalteradas dos cistos no fígado e baço. Seis dias após, o paciente sentiu dor no flanco esquerdo. Foi realizada nova ecografia abdominal, que revelou aumento no tamanho do cisto esplênico $(11 \mathrm{~cm})$. Como houve melhora no quadro da dor, o paciente seguiu em tratamento conservador. Decorridos 3 meses da última ecografia, o paciente foi internado novamente com dor em hipocôndrio esquerdo. Ao exame físico, apresentava baço palpável. Após avaliação cirúrgica, foi indicada esplenectomia, considerando o risco de ruptura do cisto e hemorragia. O procedimento foi realizado sem intercorrências. O anatomopatológico revelou baço com dimensões aumentadas, com cápsula pardo-acinzentada e lisa, medindo $18 \times 13 \times 6 \mathrm{~cm}$ e pesando $712 \mathrm{~g}$. Junto ao hilo, observou-se cisto bem delimitado com cápsula pardo-clara e fibrosa, com conteúdo de material gelatinoide e brilhante, medindo $11 \times 8 \mathrm{~cm}$ (figura 1). 0 diagnóstico foi pseudocisto esplênico não parasítico, com ausência de epitélio de revestimento e pseudocápsula colagenosa densa (figura 2). O paciente evoluiu sem complicações e permaneceu assintomático no acompanhamento pós-operatório.

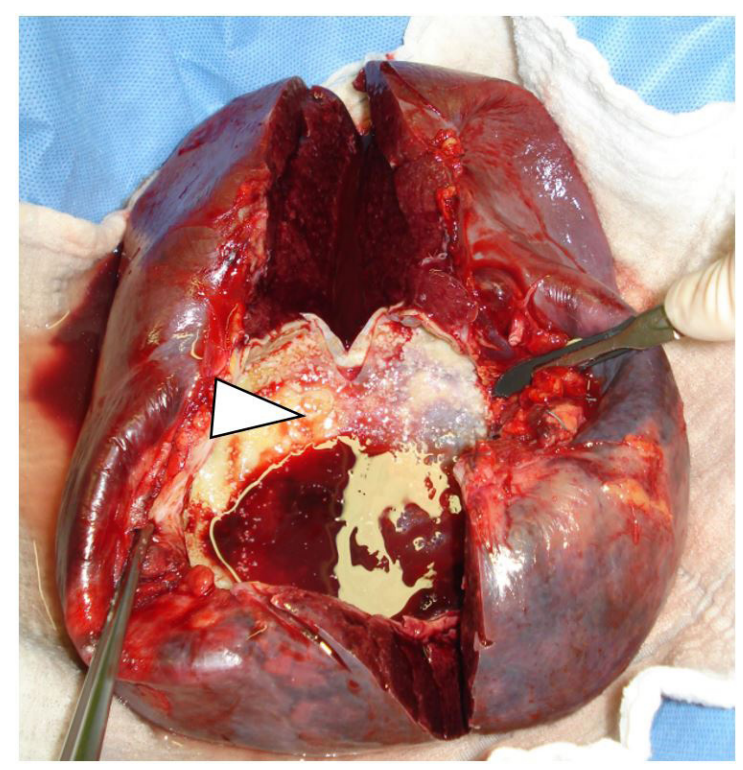

Figura 1: Cisto esplênico (seta). Cisto com cápsula pardo-clara e fibrosa (cabeça de seta).

\section{DISCUSSÃO}

Os pseudocistos correspondem a cerca de $75 \%$ dos cistos não parasitários do baço. Podem ser secundários a trauma, infecção ou infarto. A maioria deles é solitário e assintomático ${ }^{4}$. No caso apresentado, o cisto esplênico foi um achado incidental. Macroscopicamente, esses cistos são, em sua maioria, menores que cistos verdadeiros e podem conter debris internos. Microscopicamente, são compostos por tecido fibroso denso, muitas vezes calcificado, sem epitélio de revestimento. Contêm uma mistura de sangue e restos necróticos no seu interior ${ }^{5}$. O quadro clínico do paciente é compatível com os casos descritos na literatura, uma vez que cistos maiores que $8 \mathrm{~cm}$ podem causar dor no hipocôndrio esquerdo por distensão da cápsula esplênica ou por compressão de estruturas adjacentes ${ }^{6}$. É consenso que exames de imagem pouco auxiliam na diferenciação entre cistos verdadeiros e pseudocistos. O diagnóstico final foi realizado pela análise anatomopatológica. Através das ecografias, pode-se acompanhar a evolução dos cistos esplênicos e definir suas características, mas não sua etiologia. Também é possível definir a conduta a partir do exame de imagem. Devido ao risco de complicações, os cistos esplênicos com diâmetro maior que 4-5 centímetros devem receber tratamento cirúrgico ${ }^{4}$. No presente caso, optou-se por esplenectomia convencional. Por outro lado, as vantagens da cirurgia laparoscópica foram rapidamente consolidadas. Através da comparação entre esplenectomia laparoscópica e convencional, evidenciou-se que a primeira tem menor tempo operatório, menor perda sanguínea, recuperação pós-operatória mais rápida e menor tempo de internação

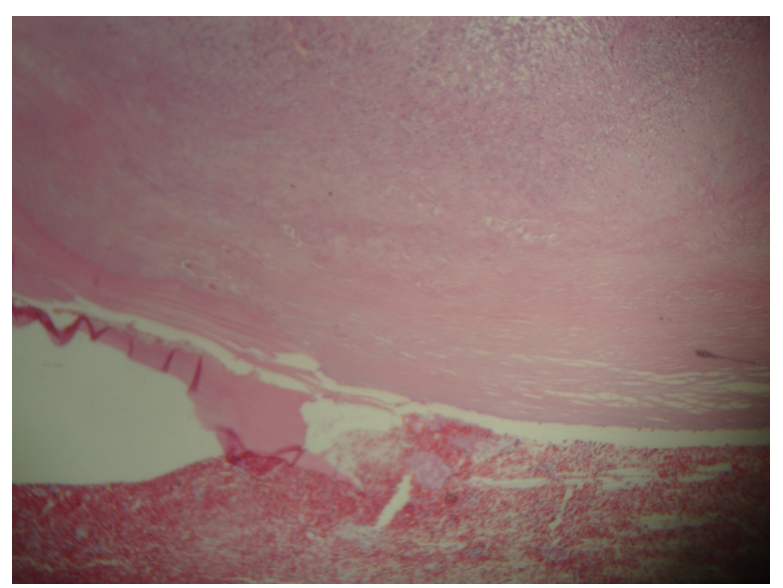

Figura 2: Anatomopatológico evidenciando pseudocisto não parasítico, sem epitélio de revestimento e pseudocápsula colagenosa densa. 
hospitalar. Não houve diferenças significativas nas taxas de complicações pós-operatórias entre os dois grupos ${ }^{7}$. As taxas de conversão relatadas para cirurgia aberta são de $25 \%^{8}$, sendo a esplenectomia laparoscópica segura e viável. Contudo, a cirurgia laparoscópica apresenta algumas limitações, como imagem bidimensional, restrição da área para movimentos com os instrumentos e posição não ergonômica para o cirurgião ${ }^{9}$. Assim, em grandes centros, a cirurgia robótica vem sendo introduzida com a finalidade de minimizar as deficiências da laparoscopia, possibilitando melhor visibilidade e destreza por possuir imagem 3D, filtros de tremores e instrumentos articulados ${ }^{10}$. Em todos os seus subgrupos, a cirurgia robótica tem menor período de internação hospitalar se comparada com as cirurgias abertas, mas o tempo de procedimento é maior ${ }^{11}$. Apesar de ser considerado um procedimento caro, quando analisamos todos os custos envolvidos, a cirurgia robótica aparenta ser custo-efetiva ${ }^{12}$. As principais complicações dos cistos esplênicos são infecção, hemorragia e ruptura ${ }^{4}$. Após a esplenectomia, os pacientes apresentam maior risco de infecções graves. As vacinas contra $S$. pneumoniae, N. meningitidis, $H$. influenzae tipo B e vírus influenza são altamente recomendadas e devem ser administradas pelo menos 2 semanas antes de cirurgias eletivas e 2 semanas após cirurgias de emergência ${ }^{13}$. O paciente apresentou boa evolução no pós-operatório. Considerando a baixa incidência dessa condição, o presente relato apresenta relevância, pois através da descrição de mais casos, pode-se conhecer melhor a história natural dessa patologia, bem como avaliar as opções diagnósticas e terapêuticas disponíveis.

\section{REFERÊNCIAS}

1. Martin JW. Congenital splenic cysts. Am J Surg. 1958;96:302-8.

2. Hansen MB, Moller AC. Splenic cysts. Surg Laparosc Endosc Percutan Tech. 2004;14:316-22.

3. Heidenreich A, Canero A, di Pasquo A. Laparoscopic approach for treatment of a primary splenic cyst. Surg Laparosc Endosc. 1996;6:243-6.

4. Schlittler LA, Dallagasperina VW. Cistos esplênicos não-parasitários. Rev Col Bras Cir. 2010;37:442-6.

5. Giovagnoni A, Giorgi C, Goteri G. Tumours of the spleen. Cancer Imaging. 2005;5:73-7.

6. Guerra MRV, Ribeiro MA, Nam MF, Casale ALV, Martins CPB,
Morais CEL, et al. Cisto esplênico não parasitário - tratamento por laparoscopia. Diagn Tratamento. 2012;17:51-5.

7. Yong F, Chen W, Lan P, Youcheng Z Applications of laparoscopic technique in spleen surgery. Eur Rev Med Pharmacol Sci. 2014;18:1713-6.

8. Koshenkov VP, Nemeth, Carter MS. Laparoscopic splenectomy: outcome and efficacy for massive and supramassive spleens. Am J Surg. 2012;203:517-22.

9. Marano A, Choi YY, Hyung WJ, Kim YM, Kim J, Noh SH. Robotic versus laparoscopic versus open gastrectomy: a meta-analysis. J Gastric Cancer. 2013;13:136-48.
10. Sodergren $M H$, Darzi A. Robotic cancer surgery. Br J Surg. 2013;100:34.

11. Salman M, Bell T, Martin J, Bhuva K, Grim R, Ahuja V. Use, cost, complications, and mortality of robotic versus nonrobotic general surgery procedures based on a nationwide database. Am Surg. 2013;79:553-60.

12. Barbash GI, Glied SA. New technology and health care costs--the case of robot-assisted surgery. $N$ Engl J Med. 2010;363:701-4.

13. Bonanni P, Grazzini M, Niccolai G, Paolini D, Varone O, Bartoloni $A$, et al. Recommended vaccinations for asplenic and hyposplenic adult patients. Hum Vaccin Immunother. 2017;13:359-68.

Recebido: Mar 10, 2017 Aceito: Abr 30, 2017 